\title{
EARTHQUAKE ANALYSIS ON 2D RC FRAMES WITH DIFFERENT ASPECT RATIOS OF MASONRY INFILL AND MONOLITHIC PANEL
}

\author{
Md.Khaja.M ${ }^{1}$, Chethan.K ${ }^{2}$, Ramesh Babu ${ }^{3}$ \\ ${ }^{1}$ Department of Civil Engineering, B.K.I.T, Bhalki, mohammed_khajarec@yahoo.com \\ ${ }^{2}$ Assistant Professor Department of Civil Engineering, U.V.C.E, Bangalore, k.chethu@gmail.com \\ ${ }^{3}$ Additional Director, E.V.R.C CPRI, Bangalore, rbabu@cpri.in
}

\begin{abstract}
$R C$ structures are one of the most famous and most utilized types of construction throughout the world. The wall panels for this type of structures usually are made of masonry infill or monolithic RC panels. In this paper, earthquake analysis of a typical $2 D$-RC frame is carried out. Masonry infill is modeled as equivalent diagonal strut and monolithic panel is modeled as shell element. Modal analysis is carried out on the models and the results are compared with the shake table tests conducted at Central Power Research Institute (CPRI), Bangalore to validate the models. Earthquake analysis is continued with equivalent static, response spectrum and time history analyses for all the zones (II-V) as per IS: 1893(Part-1):2002. The analysis results such as natural frequency, displacement, interstorey drift and acceleration are tabulated, compared and conclusions are drawn.
\end{abstract}

Key words: 2D-RC Frame, Masonry Infill, Monolithic wall, Shake table, Natural Frequency, Modal analysis, Response spectrum, Equivalent Diagonal Strut, Time History, Inter-Storey drift.

\section{INTRODUCTION}

Reinforced concrete frame buildings with masonry infill panels are generally regarded as 'Earthquake Risk' buildings. As such there is a growing need to carry out an evaluation of their level of seismic performance. In recent years there has been a good deal of research in the area of infill-masonry buildings. Guidelines have also been published recently for the seismic evaluation of these structures. A literature review indicated that the current 'state-of-the-art' in practice is to account for infill panels by including an equivalent strut to represent the stiffness of the panels. There are however a range of proposed modeling methods. The earthquake damage of the in filled frame structures usually results from ignoring the stiffening effect of the infill, which is reported to increase the stiffness of the bare frame 4 to 20 times, [Comite EuroInternational Du Beton, (1996)].

\section{MODELING OF MASONRY INFILL}

In the case of an infill wall located in a lateral load resisting frame the stiffness and strength contribution of the infill are considered by modeling the infill as a an equivalent compression strut. The infill parameters are effective width, elastic modulus and strength were calculated using the method recommended by Chethan.K the length of the strut is given by the diagonal distance "d" of the panel and thickness is given by the thickness of the infill wall. The estimation of the width of the strut is given in equation 1. Parameters $\alpha_{h}$ and $\alpha_{1}$ are given below are used to calculate the effective width

$$
w=\sqrt{\alpha_{L}^{2}+\alpha_{h}^{2}}
$$

Here,

$$
\begin{array}{r}
\alpha_{h}=\frac{\pi}{2 \lambda} \\
\lambda=\sqrt[4]{\frac{E_{m} t \sin 2 \theta}{4 E_{c} I_{c} h}}
\end{array}
$$

Beam contact length ' $\alpha_{\mathrm{L}}$ ' is taken approximately half of its span.

Where, $\mathrm{t}, \mathrm{h}, 1$ and $\mathrm{d}$, are respectively the thickness, height, length and diagonal length of $\mathrm{MI} ; \mathrm{E}_{\mathrm{m}}, \mathrm{E}_{\mathrm{c}}$, and $\mathrm{E}_{\mathrm{L}}$ are the Modulus of elasticity of MI, column and beam respectively; $I_{c}$ and $\mathrm{I}_{\mathrm{L}}$ are Moment of inertia of the column and beam respectively. The slope of infill diagonal to horizontal is $\theta=$ $\tan ^{-1}(\mathrm{~h} / \mathrm{L})$. Also, $\lambda_{\mathrm{h}}$ is coefficient used to determine equivalent $\theta=\tan ^{-1}(\mathrm{~h} / \mathrm{L})$ width of infill strut, $\lambda_{\mathrm{L}}$ is empirical parameter expressing the relative stiffness of the beam to the infill and $\alpha_{\mathrm{h}}$ is the relative stiffness of the infill to frame

\section{ANALYTICAL MODELLING}

The 2D RC Frames used for analysis are of one-bay, one to five storey with different aspect ratios of $0.7,1.0$ and 1.3. The length of beams is $2.4 \mathrm{~m}$ for all frames and the length of columns are $1.68 \mathrm{~m}, 2.4 \mathrm{~m}$ and $3.12 \mathrm{~m}$ respectively. The boundary condition is fixed. Table 1 shows member properties and structural details. Fig. 1 shows the model details 
Table.1: Member Properties and Structural Details

\begin{tabular}{||l|c|c|c|l|l||}
\hline \hline \multicolumn{5}{||c|}{ Member Properties } & \multicolumn{2}{c||}{ Structural Details } \\
\hline Member & $\begin{array}{c}\text { Diameter } \\
\text { of bar }\end{array}$ & $\begin{array}{c}\text { Number } \\
\text { of Bars }\end{array}$ & $\begin{array}{c}\text { Cross-section } \\
\text { in mm }\end{array}$ & Main Reinforcement & Stirrups/Lateral Ties \\
\hline Column & $12 \mathrm{~mm}$ & 6 & $115 \mathrm{~mm} 230 \mathrm{~mm}$ & $\begin{array}{l}\text { 6-12mm bars } \\
\text { throughout the length } \\
\text { of the column }\end{array}$ & $\begin{array}{l}\text { 2 legged 6 mm @ a } \\
\text { spacing of 75 mm c/c } \\
\text { throughout }\end{array}$ \\
\hline Beam & $12 \mathrm{~mm}$ & 4 & $115 \mathrm{mmx} 230 \mathrm{~mm}$ & $\begin{array}{l}\text { 4-12mm bars } \\
\text { throughout the length } \\
\text { of the beam }\end{array}$ & $\begin{array}{l}\text { 2 legged 6 mm @ a } \\
\text { spacing of 75 mm c/c } \\
\text { throughout }\end{array}$ \\
\hline Masonry & $115 \mathrm{~mm}$ & --- & --- & & \\
\hline
\end{tabular}

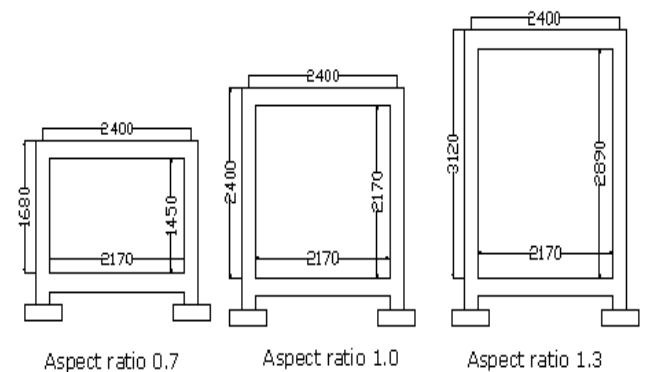

Fig.1: 2D RC frame with detailed dimensions for different Aspect Ratios

The different configurations of Bare Frame (BF), Masonry Infill (MI), Masonry Infill with Soft Storey (SMI), Monolithic Panel (MP) and Monolithic Panel with soft Storey (SMP) are analyzed. Results obtained for model with one bay and one storey for BF and MI are validated with the Shake table results.

\section{LOADS}

Analysis of the frames is done using SAP 2000 software. Dead load and Earthquake load are considered for analysis.

i) Dead load (DL)

The dead load is considered as per IS 875-1987 (Part I-Dead loads)

- Unit weight of Reinforced Concrete $=25 \mathrm{kN} / \mathrm{m}^{3}$

- Unit weight of Brick $=19.2 \mathrm{kN} / \mathrm{m}^{3}$

ii) Earthquake Load (EL)

The earthquake load is considered as per the IS 1893(Part 1): 2002 the factors considered are

- Zone factors $=0.10,0.16,0.24,0.36$ (zone II-zone V)

- Importance factor

$$
=1.0
$$

- Response reduction factor

$=5.0($ S.C.R $)$

- Soil condition

$=$ Soft soil

- Damping

$$
=5 \%
$$

\section{GENERATION OF TIME HISTORY AND RESPONSE SPECTRA}

Design response spectrums are developed for zone II, III, IV and $\mathrm{V}$ for the two axes and are fed into the Desired File Generator (DFG) software. The DFG software converts the required response spectrum into the time history, which is in terms of acceleration. Typical time history for zone-II is as shown in Fig.2.

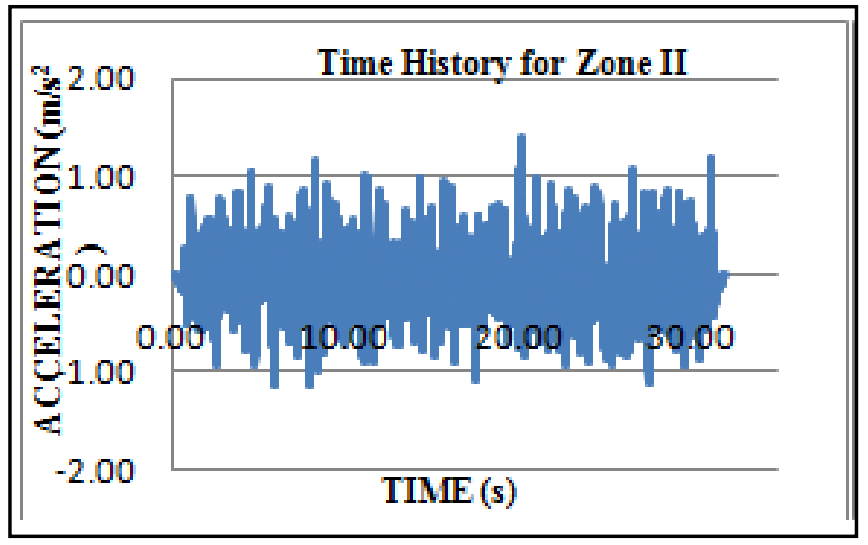

Fig 2: Time history for Seismic Zone-II

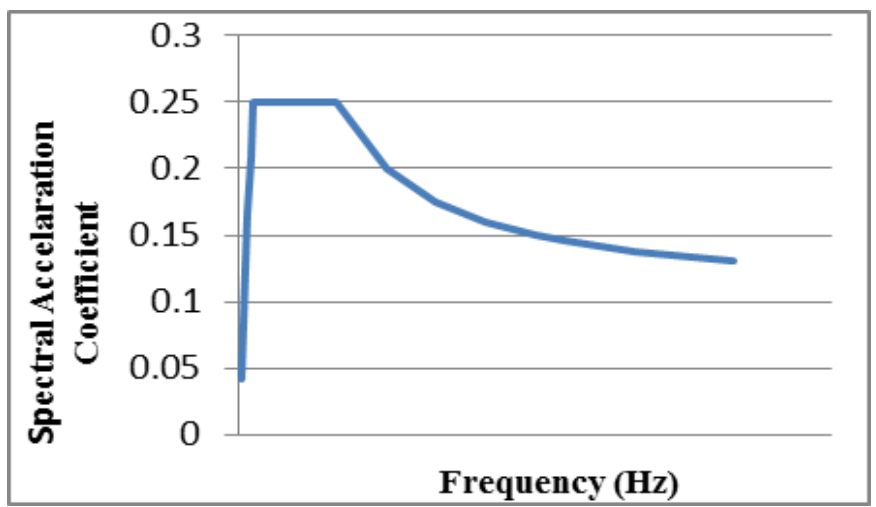

Fig.3: Design Spectrum for Seismic Zone-II 
For analyzing the 2D-RC frame subjected to seismic loading, the design response spectra is obtained as per the recommendations of IS 1893 (Part1): 2002 titled "Criteria for Earthquake Resistant Design of Structures". The typical design response spectrum for seismic Zone-II is as shown in Fig.3.

\section{RESULTS AND DISCUSSIONS}

Nonlinear static analysis is performed to determine the lateral load resisting capacity of the structure and nonlinear dynamic analysis is performed to evaluate seismic performance of bare, infill frame and monolithic panel model.

From this analysis the modal parameters such as natural frequencies and mode shapes are obtained. Sine sweep tests are conducted on the $\mathrm{RC}$ frames using shake table to evaluate the natural frequencies experimentally which are later analyzed using software for validation. The natural frequencies obtained using shake table and software for different models are compared in Table.2.

Table.2. Comparison of Natural Frequency

\begin{tabular}{|c|c|c|c|c|}
\hline \multicolumn{5}{|c|}{ FOR BARE FRAME } \\
\hline \multirow[b]{2}{*}{$\begin{array}{l}\text { Aspect } \\
\text { ratio }\end{array}$} & \multicolumn{2}{|c|}{ In- plane } & \multicolumn{2}{|c|}{ Out of plane } \\
\hline & $\begin{array}{l}\text { Shake } \\
\text { Table }\end{array}$ & $\begin{array}{c}\text { Modal } \\
\text { Analysis }\end{array}$ & $\begin{array}{l}\text { Shake } \\
\text { Table }\end{array}$ & $\begin{array}{c}\text { Modal } \\
\text { Analysis }\end{array}$ \\
\hline 0.7 & 24.00 & 24.773 & 7.00 & 7.188 \\
\hline 1.0 & 14.00 & 14.789 & 3.75 & 4.166 \\
\hline 1.3 & 10.25 & 10.865 & 2.00 & 2.726 \\
\hline
\end{tabular}

\begin{tabular}{|c|c|c|c|c|}
\hline \multicolumn{4}{|c|}{ FOR MASONRY INFILL FRAME (MI) } \\
\hline \multirow{2}{*}{$\begin{array}{c}\text { Aspect } \\
\text { ratio }\end{array}$} & $\begin{array}{c}|c| \\
\text { In- plane } \\
\text { Table }\end{array}$ & $\begin{array}{c}\text { Modal } \\
\text { Analysis }\end{array}$ & $\begin{array}{c}\text { Shake } \\
\text { Table }\end{array}$ & $\begin{array}{c}\text { Modal } \\
\text { Analysis }\end{array}$ \\
\cline { 2 - 5 } & 29.00 & 30.77 & 4.00 & 4.800 \\
\hline 0.7 & 22.00 & 22.75 & 2.00 & 2.581 \\
\hline 1.0 & 15.00 & 15.78 & 1.25 & 1.612 \\
\hline 1.3 & & & & \\
\hline
\end{tabular}

From the above Table 2, it is observed that the natural frequency obtained from modal analysis matches well with the shake table test results and hence the models are validated and the models so developed are further analyzed for different configurations. The number of storey of all the models is increase from one storey to five storeys.

\section{a) Natural Frequency in In-Plane Direction}

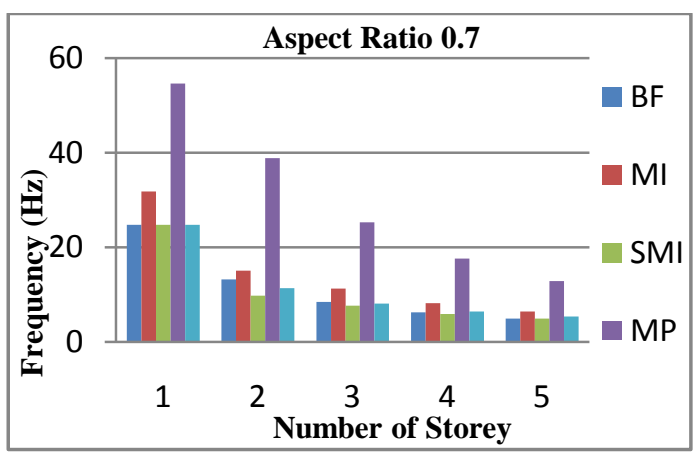

(a)

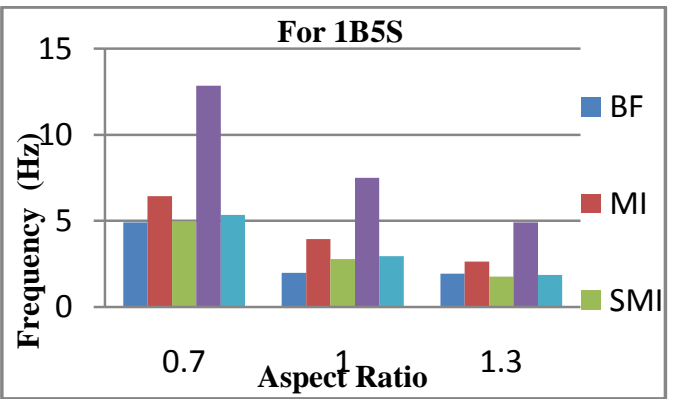

(b)

Fig.4: In-Plane Natural frequency $(\mathrm{Hz})$

From above graphs as the number of storeys increases the natural frequency of the frame decreases, also when the aspect ratio increases natural frequency decreases due to the increase in the mass of the frame. The natural frequency of frame SMI decreases by $30 \%$ compare to bare frame which are nearly equal in SMP, whereas the natural frequency of MP frame is more than double the frequency of the BF. The MP has the highest natural frequency followed by MI, SMP and SMI as the masonry in fills and the monolithic panel adds stiffness to the structure. As the stiffness increases in the in-plane direction, the natural frequency increases. Hence it is clearly observed that the MI has a role in the earthquake response of the structure. 


\section{EARTHQUAKE RESPONSE OF 2D-RC FRAME}

To determine the earthquake response of the $2 \mathrm{D}-\mathrm{RC}$ frame for different configuration it is analyzed for the all seismic zones as specified by the IS:1893(Part-1):2002. The models have been analysed by Equivalent Static Analysis from which the Static base shear have been extracted, then by Response Spectrum Analysis the Dynamic base shear have been obtained for a scale factor of 1 . Inter-Storey drift is calculated using the following formula,

\section{a) Displacement in In-Plane direction}

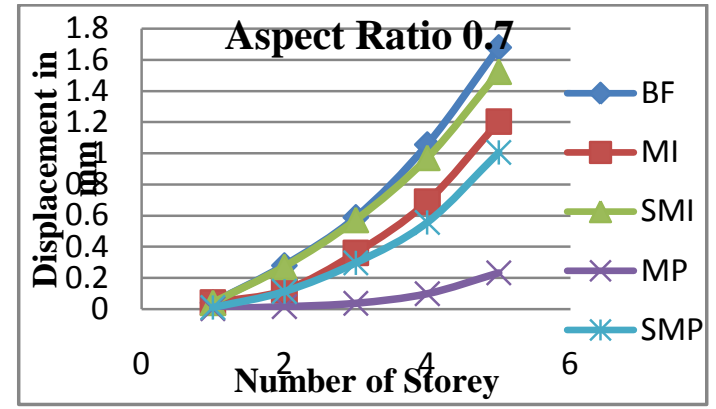

(a)

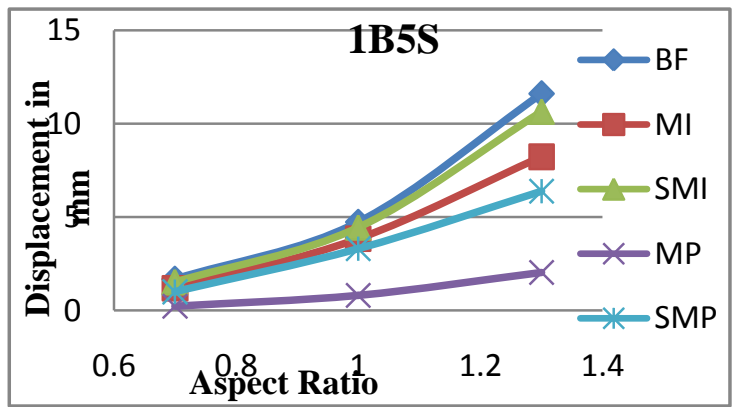

(b)

$$
\mathbf{S}_{\mathrm{Di}}=\Delta_{\mathrm{i}}-\Delta_{\mathrm{i}-1}
$$

Where, $\Delta_{\mathrm{i}}-\Delta_{\mathrm{i}-1}=$ horizontal displacement $\mathrm{h}_{\mathrm{i}=}$ floor height the values obtained for inter-storey dirft are tabulated and compared

Fig.5: Comparison of In-Plane Displacement (mm)

From Fig.5, it is observed that the displacement in the soft storey is maximum in the lower storeys as compared to the other two conditions (i.e. MI and MP) which show its criticality in the earthquake resistant design. As the mass increases, displacement decreases. As the aspect ratio increase from 0.7 to 1.0 , displacement of the frame increases by $32 \%$ in BF, SMI and SMP, whereas it increases by $43 \%$ in MI and MP. When the aspect ratio changes from 1.0 to 1.3, displacement increases by $45 \%$ in BF, SMI and SMP, which also increases by $36 \%$ in MI and MP. This indicates that the $\mathrm{BF}$ is having maximum displacement because of less stiffness. SMI, SMP, MI and MP are having less displacement values because of more stiffness.

\section{b) Out of Plane Inter-Storey Drift}

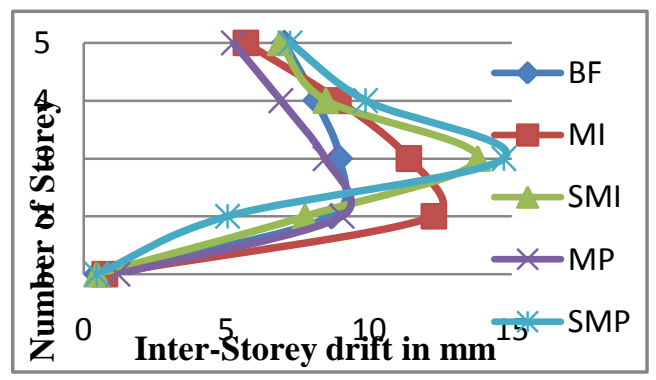

Fig.6: Comparison of Inter-storey drift ( $\mathrm{mm}$ ) for Aspect Ratio 0.7

It is observed that the inter-storey drift in the MI are higher compared to BF and MP, but less than SMI and SMP. Due to the presence of soft storey in first floor, the inter-storey drift of SMI and SMP is maximum in the third floor as compared to $\mathrm{BF}, \mathrm{MI}$ and MP which has the maximum inter-storey drift at second storey. As the aspect ratio increase from 0.7 to 1.3 the inter-storey drift decreases by $16 \%$.

\section{c) Acceleration in In-Plane direction}

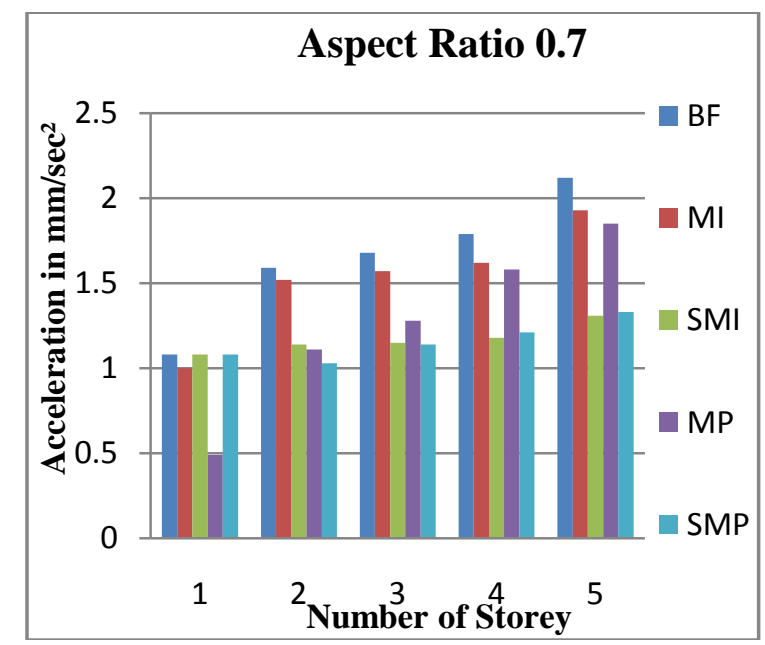

(a) 


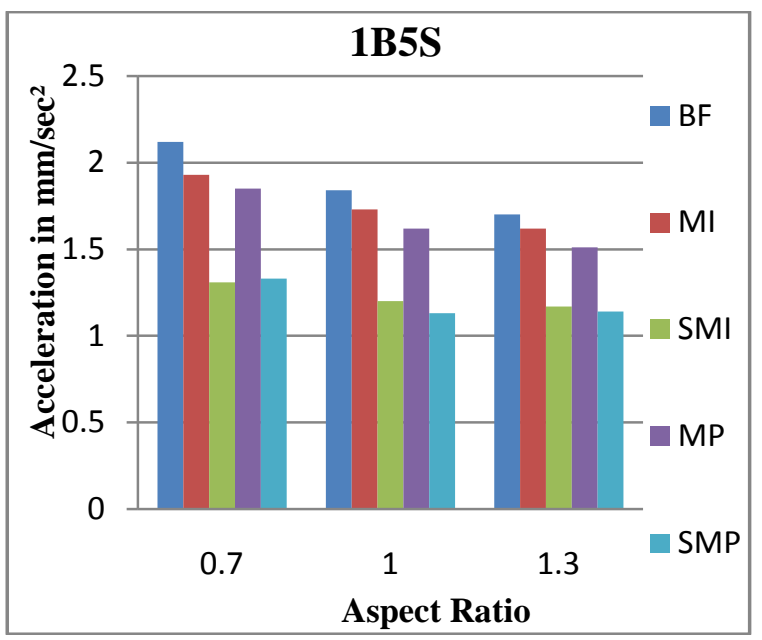

(b)

Fig.7: Comparison of In-Plane Acceleration

It indicates that the acceleration increases with increase in the number of storey for all configurations. But when the aspect ratio increases the acceleration decreases. $\mathrm{BF}$ is having high acceleration value because of less mass. SMP is having less acceleration value followed by SMI, MP and MI because of more mass. When the frame is provided with soft storey (i.e. SMP, SMI) the acceleration is nearly equal. When the aspect ratio increases from 0.7 to 1.0 the acceleration decreases by $14 \%$, whereas when it increases from 1.0 to 1.3 the acceleration decreases by $9 \%$.

\section{TIME HISTORY ANALYSIS RESULTS}

The Time History is from response spectrum as per IS: 1893(Part- 1):2002 by using DFG software and used for analysis. The Displacements and Accelerations obtained from the Time History Analysis for Zone-V compared in Fig.1.8.

\section{a) Displacement in the In-plane direction}

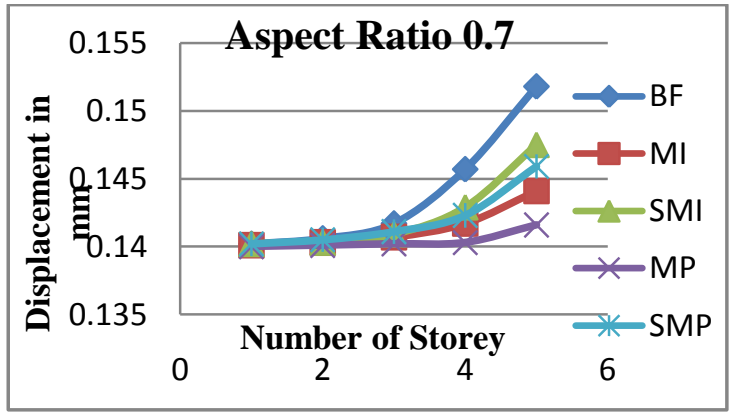

(a)

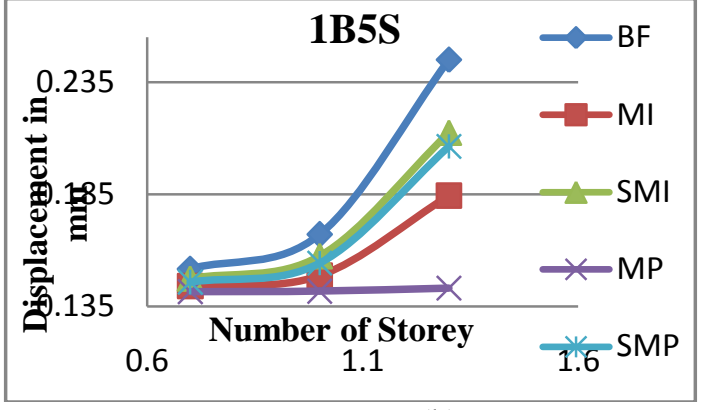

(b)

Fig.8: Comparison of In-Plane Displacement (mm)

It is observed that the $\mathrm{BF}$ is having maximum displacement because of less stiffness, followed with SMI and SMP compare to MI and MP. With the increase in the number of storeys, the displacement of the frame increases by $7 \%$, also when the aspect ratio increases the displacement increases. As the aspect ratio increase from 0.7 to 1.0 , displacement of the frame increases by $5 \%$ in all configurations whereas when the aspect ratio changes from 1.0 to 1.3 , displacement increases by $20 \%$. MI and MP are having minimum displacement values because of more stiffness. From this we can clearly understand that the displacement decreases as the stiffness increases.

\section{b) Acceleration in the In-plane direction}

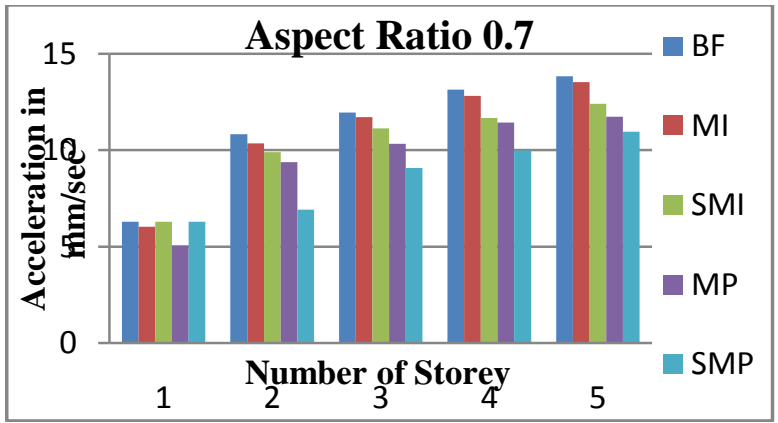

(a)

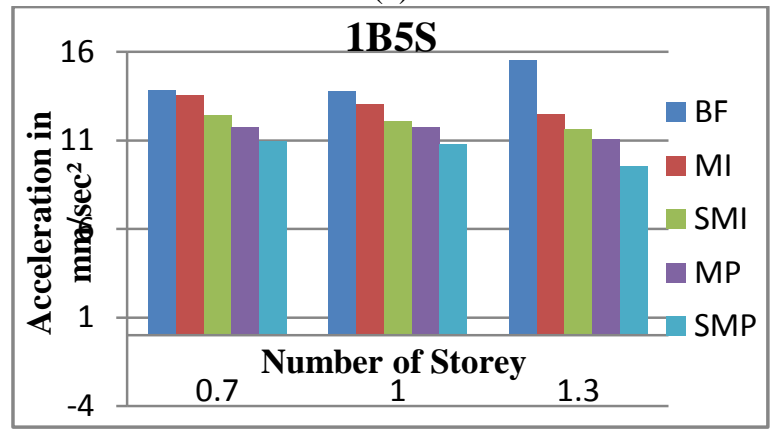

(b)

Fig9: Comparison of In-Plane Acceleration ( $\mathrm{mm} / \mathrm{sec}^{2}$ )

It is observed that as number of storey increase the acceleration increases for all configurations. The BF is having high acceleration value because of less mass, whereas SMP is having least acceleration value followed by MP, SMI and MI 
because of more mass. With the increase in the aspect ratio from 0.7 to 1.0 the acceleration decreases in all models, whereas when aspect ratio increase from 1.0 to 1.3 acceleration increases in BF and MI only. MP is having less acceleration value because of its mass.

\section{CONCLUSIONS}

1) From the modal analysis, it is found that the natural frequencies of the infill frame are around twice when compared to bare frames.

2) As the aspect ratio increases the natural frequency decreases in both in-plane and out of plane direction, due to increase in the mass of the frame.

3) The inter-storey drift in the first storey are large for soft storey compared to BF, and SMI frame which shows the sudden change in slope of drift, this is due to the abrupt change in storey stiffness, whereas the MI, MP and SMP frame shows a smooth profile.

4) From time history analysis, it is found that the large displacement occurs in the soft storey compared to bare frame and infill frames due to the abrupt change in storey stiffness.

5) Of all seismic zones considered (Zone II to Zone V), Zone- $\mathrm{V}$ is the critical zone with highest base shear, acceleration and displacement.

\section{REFERENCES}

[1] Amit V Khandve, Seismic Response of RC Frame Buildings with Soft Storeys, IJERA, Vol. 4 (3), MayJun 2012, pp.2100-2108.

[2] Chethan K, Study on Dynamic Characteristics of 3D Reinforced Concrete Frame with Masonry Infill, Journal of CPRI, Vol 5 (2), September 2009, pp. 11-18

[3] Sharany Haque and Khan Mahmud Amana, Strength and drift demand of columns of RC framed buildings with soft ground story, IEB, Vol. 37, January 2009 (2), pp 99-110.

[4] Smith B S and Carter C, A method of analysis for infilled frames, Proceedings of the Institute of Civil Engineers, Vol. 44, 1969, pp. 31-48. 